\title{
A Process of Demographic and Economic Polarization in the Republic of Macedonia ${ }^{1}$
}

\author{
Mirjanka Madzevic ${ }^{\mathrm{A}}$, Biljana Apostolovska -ToshevskaA, Dejan Iliev ${ }^{\mathrm{A}}$ \\ Received: April 2013 | Revised: June 2013 | Accepted: June 2013
}

\begin{abstract}
Demographic and economic development in the Republic of Macedonia is characterized by high dynamics, and imbalance in development. The unequal social and economic development is one of the main negative features of development, especially during the transition period in which the regional development has been marginalized on the expense of market development and stabilization and restructuring of the economy. Equally important component of the development is the problem of concentration and dispersion of population and economic activities in the area causing the appearance of demographic and economic polarization in the country. Today, the degree of the population and economic development in the Republic of Macedonia shows certain differences on a regional level, according to distribution of the population, investments, GDP and etc. From the available social and economic indicators can be concluded that the Republic of Macedonia has the characteristics of a country with a mono-centric model of development where the Skopje region stands out as the core of development, while other regions stagnate or grow with less intensity compared to the previous one. Therefore, this current problem requires finding solutions for reducing the disparities in the regional development and harmonization of the same.
\end{abstract}

Key words: Macedonia, population, economic, polarization

\section{Introduction}

The contemporary demographic and economic condition in the Republic of Macedonia is a result from an extensive mutual acting of few components, mainly the natural environment and the complex socio economic processes. That is, the characteristics of the natural basis that the Republic of Macedonia possesses, together with the demographic - settlement, the socio - economic and the spatially - functional occurrences and processes have strong influence on the change in the numeral movement, the displacement and the structural notes of the population and the economic development of the country.

Starting from the second half of the twentieth century and onwards in the Republic of Macedonia, sig- nificant spatial - demographic and economic changes are carried, closely related to the primary urbanization and the intensive migration of the population. The process of relocation of the population from the villages to the cities, from lesser developed areas to areas with higher level of economic development, with greater and various possibilities for employment resulted with a deepening of the regional differences in every aspect. Especially here the following can be observed: from one side the tendency for concentration of the population and the material goods, mainly in the bigger urban centers, and from the other side the permanent emptying and falling behind of other areas. Giving a priority to certain economic branches, first of all the industry as a carrier of the economic growth,

\footnotetext{
1 The paper is presented at the 32nd International World Congress of Geographers in Cologne, Republic of Germany (26 - 30 August, 2012).

A Ss. Cyril and Methodius University, Faculty for Natural Sciences and Mathematics, Institute of Geography, Gazi Baba bb 1000 Skopje, Republic of Macedonia

e-mail: mira.madzevikj@gmail.com, biljana.apostolovska@gmail.com, d.iliev@hotmail.com
} 
the thesis for the double value of the workplace in industry (Kartalov, 1996) was more and more confirmed. From there, the industry was encouraging the other sectors, all of them together stimulated the demographic polarization, and the demographic polarization was bringing economic polarization. Of course, these processes are characteristic for many countries in the region and further. For example in neighboring Bulgaria there is a big difference between population and economic development between the northern and southern regions. "There is a clear-cut polarization in the population concentration" (Mladenov, 2002). The Southwest region, which includes the capital, on $18.3 \%$ of the territory of the state lives almost $30 \%$ of the total population, the existing $18 \%$ of all settlements (Project "Development of socio-economic analysis of the needs of the Regional Development Operational Program for the period 2014-2020", p. 17) and in 2009 the region by GDP and GDP per capita is above the national average (Regional profiles "Development Indicators", Sofia, 2012, p. 29). Along with the Southern central region on $38.5 \%$ territory lives nearly half of the Bulgarian population. During the nineties of the 2oth century, $74 \%$ of central Serbia's territory underwent major depopulation processes, despite the large populated areas around urban centers, especially in the Belgrade region (Vojković, 2007). Similar is the situation in Albania where nearly $2 / 3$ of the population was concentrated in the west, especially in Tirane-Durres region (http://www.nationsencyclopedia.com/economies/ Europe/Albania.html), than Bosnia and Herzegovina (Nurković, 2006) and other countries.

This polarization as a process, while it is well controlled, presents a basis for functional integration of the economic and social activities, prompting the overall development. From the other side, in the lack of planned social influence, often an uncontrollable super - concentration is created that brings significant problems related to rational, economical use of the material, spatial and human resources imposed, which further leads to ecological, economical, demographical and overall imbalance.

\section{Data Source}

During the making of this study, published data from the State Statistical Office have been used in order to help with the analyzed time period. For reviewing the data by regions, it was worked according to the NUTS - 3 classifications where eight statistical - planning regions were singled out.

Taken into account are few elements through which the resulting regional demographic - economic changes can be seen, such as: number dynamics, density of population, rate of natural increase, number of business subjects, investments, total - added value and gross domestic product per capita.

Considering the fact that the last census of the population in the country was done in 2002, for recognizing of the newest state of the number of population and its displacement within regions, analyses that are based on evaluations of the population are given.

At the same time for preparation of the cartographic displays, the program package ARCGIS was used.

\section{Discussion and results}

In view of the spatial distribution of the population and the economic pointers in this country, can be noticed a serious - emphasized heterogeneity, where the densely populated centers especially Skopje and the few bigger cities, are permanently population - wise increasing and stand out as areas that absorb considerable demographic, but also economic potential that enables for them to grow into regional centers. On the other side, there are a great number of populated areas that have smaller population and have been in stagnation or have even been depopulating. The bigger cities cover relatively small surface, but most of the population is concentrated here, and stand out in term of its total influence on the surrounding space. One third of the total population was concentrated mainly in the five biggest cities (Skopje, Bitola, Kumanovo, Prilep and Tetovo) in this country whose size in 2002 surpassed 50,000 inhabitants. The depopulated areas, that are characterized with: smaller population density, tendency for lowering of the number of inhabitants, lowering of the natural increase, rapid process of ageing and worsening of the demographic structure; today are spread on a relatively large area. Besides the high number of depopulated villages that in 2002 presented $8 \%$ from the total number of populated areas, especially worrying is the condition with the smallest populated areas. More precisely, in 455 populated areas that had one to fifty inhabitants and presented $25.8 \%$ from the total populated areas lived only 0.5\% of the total population. In this manner, on the territory of the Republic of Macedonia, the process of demographic and at the same time economic polarization is being developed and deepened.

When it comes to demographic changes in certain regions, the analysis of the total population indicates a different population changes that exist between the regions themselves and within the regional framework. The increase of the population in the period between the last two censuses $1994-2002$ is characteristic for all the regions except for the Pelagonija Region where the average annual rate of increase of the population was -0.23, opposed the growth rate of the total population in the Republic of Macedonia 


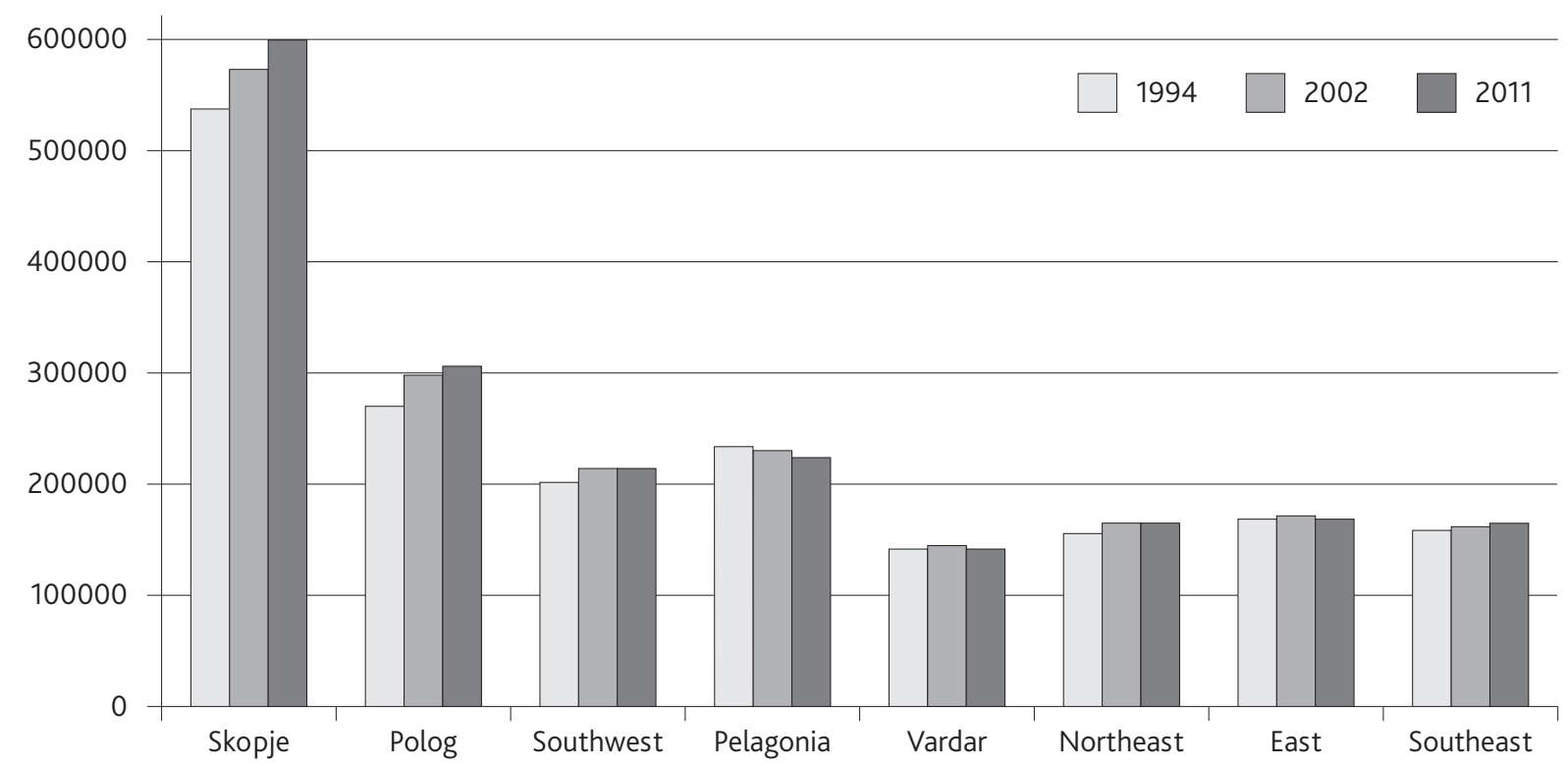

Figure 1. Number of the population in regions in Republic of Macedonia, 1994, 2002 and 2011

Source: according to data from the State Statistical Office of the Republic of Macedonia

that was $0.48 \%$, as is for two thirds of the municipalities in the country (Figure 1). The highest growth rate, that is higher than the national growth have the Polog with $1.02 \%$, Skopje $0.73 \%$ and Northeast with $0.73 \%$. In the next period, the changes are kept in the same direction (Figure 2).

The changes in the total rate are conditioned from the tendencies in the natural movement and the different dynamics of the migrations. The natural movement as an important element of the demographic dynamics in the recent period suffered strong changes with basic characteristic of decrease of the birth rate and increase of the death rate, mainly specified by the age structure of the population.
The permanent lowering of the birth rate and with it the natural growth has noticeable regional differences. In that direction, the Pelagonija region features the most unfavorable condition because the natural growth has negative value from $-3 \%$ in 2011 . Also, in the Eastern and Vardar region, the number of dead persons has already surpassed the number of newborns. On the other side, the Polog with $3.8 \%$ and the Skopje with $4.3 \%$ have highest rate of natural increase. On a national level, the natural increase was very low with worrying value of only $1.6 \%$ in 2011.

In view of the migratory movements as a component in the demographic dynamics, we can emphasize that the emigration from this country in the past,

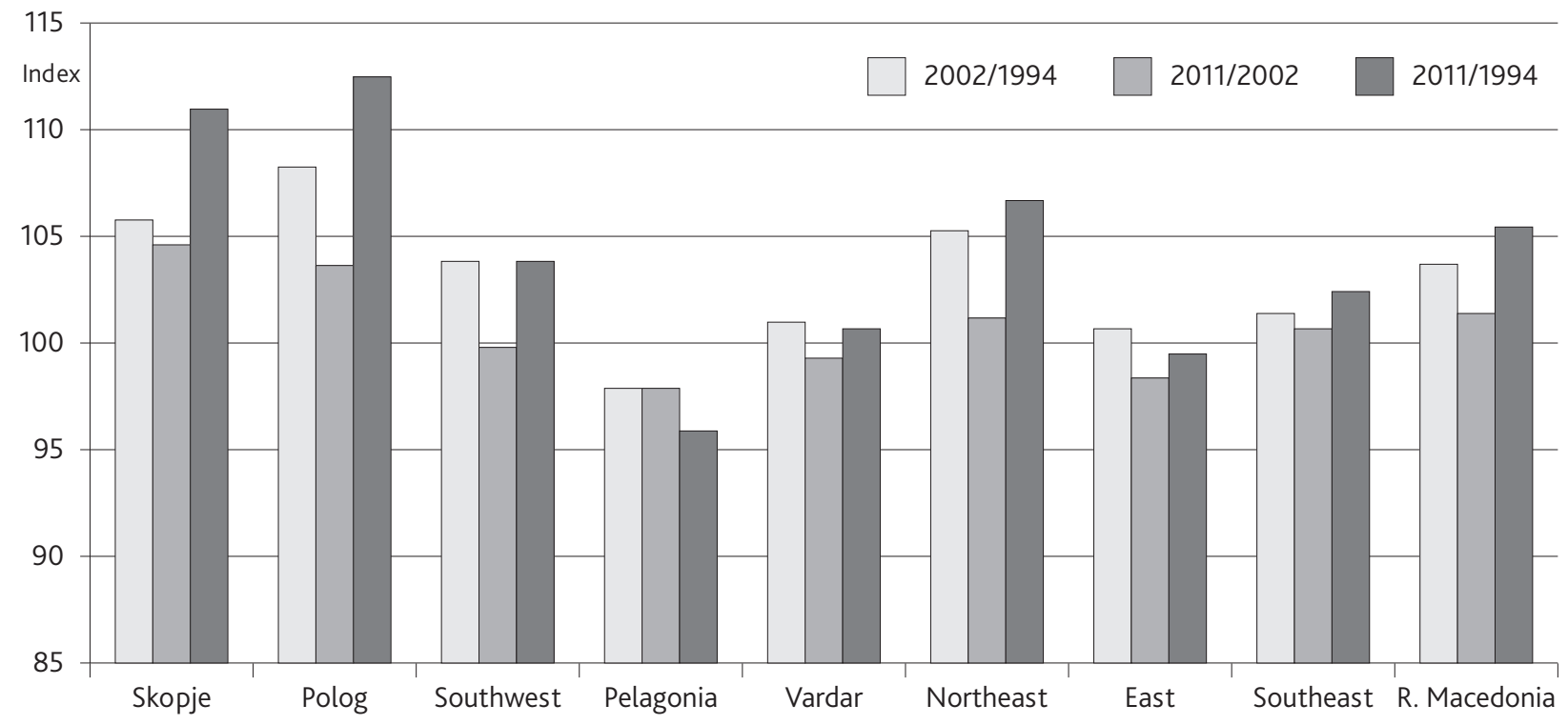

Figure 2. Change of the population by regions

Source: according data from the State Statistical Office of the Republic of Macedonia 


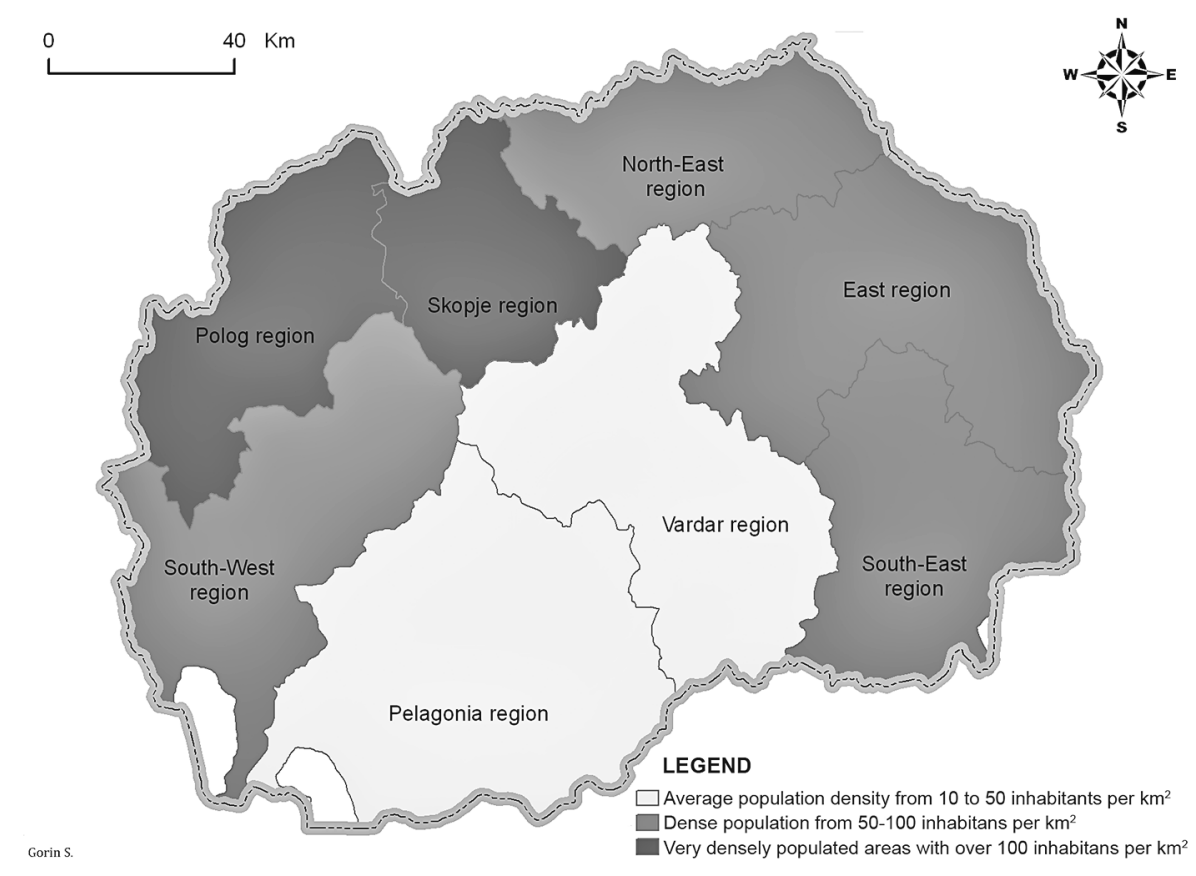

Map 1. Density of the population by regions

Source: according to data from the State Statistical Office of the Republic of Macedonia

together with the internal in-between - regional displacement movements that were greatly directed towards the Skopje region, influenced the number dynamics and the regional differences. The Pelagonija region stands out as a region with long term emigration of the population that left its mark on the overall demographic condition. According to the newest data, only the Skopje region has a positive migratory balance, the Southwest and Southeast have a balance close to zero, and the rest of the regions have a negative value.

Everything mentioned above has its mark on the different participation of the regions in the total population. Actually, there was a change in the spatial distribution of the population, the participation of the population from the regions in the total population of the country, through expressed decrease of the Pelagonija, Vardar, Southeast and East regions. With the other regions an increase in the concentration of the population can be noticed, that is greatest in the Polog region.

The largest part of the population in the country is permanently concentrated in the Skopje region, which because of its small size features the highest population density, which is four times the national average (Map 1). In second place by the share in the total population is the Polog region, with slightly larger area than the Skopje region and population density above the state average. These two regions actually notice increase in the concentration of population in the recent period and are the only that are characterized by increasing their share in the total population of the country. In the other regions the share of the population is in stagnation or is declining and it is usually smaller than the territory they occupy, which contributes to feature lower value of density of the population.

Big part of the population in the state is concentrated in the Northeastern region, the Skopje region and Polog region. Their share has increased from $50.8 \%$ in 1994 to $52.1 \%$ in 2002 and $53.3 \%$ in 2011. This represents a huge concentration of population in only $26.3 \%$ from the territory of the country. These three regions stand out in relation to the rest of the area of the country for its extraordinary great concentration of population (Figure 3).

A more wholesome representation can be achieved through an analysis of municipalities and populated areas where the differences can be noticed in the frames of the region itself. There are zones of geographical agglomeration (growth and development), as are areas with emphasized territorial dilution, or settlement, population and economic stagnation. Mainly, the eight regional centers and the bigger city settlements are centers of concentration, and the rural areas are the ones being emptied. But, of course, the new spatial - functional and demographic processes should be taken into consideration. The increase of the attractiveness of certain locations, especially those near the bigger cities bring to their population and functional strengthening, as opposed to the demotion of the rural area that is a precondition for a depressive economic geographic development.

In the contemporary socio - economic sphere new functional relations are being developed between the 


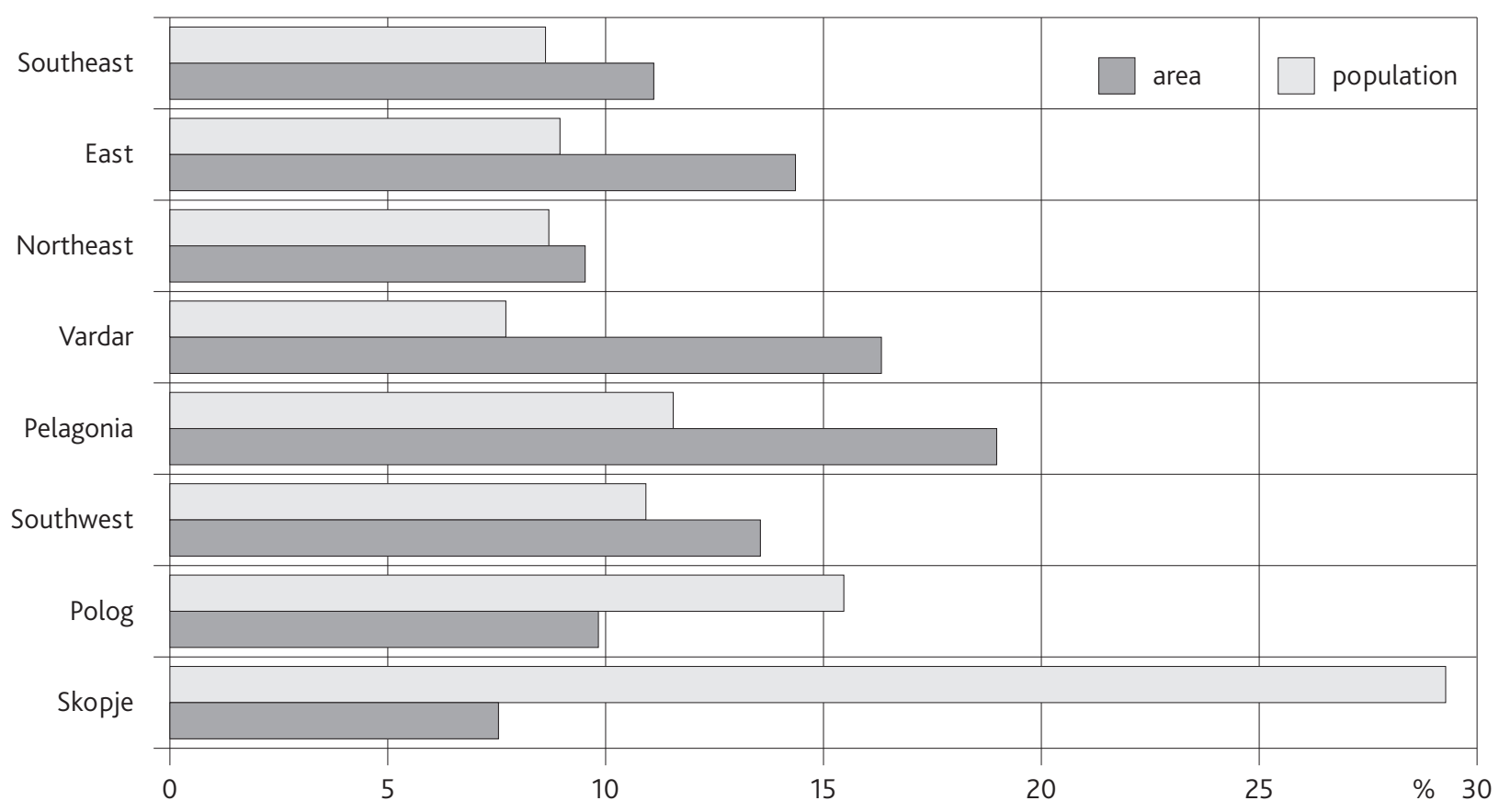

Figure 3. Percentage share of regions in total area and population of the Republic of Macedonia, 2011 Source: according data from the State Statistical Office of the Republic of Macedonia

separate spatial units. The previous misbalanced regional development means a basis for developmental disproportions, considerable economic geographic disintegration and increase of the non - valorized potentials of the national territory.

In the Republic of Macedonia, the greatest attractive force in economic terms is the Skopje region for its infrastructural equipment, also because of its loca- tion and the good connectivity with the other centers from the former Yugoslavia. Thus, most of the industrial facilities were located in the capital and its surrounding areas. In 2010, half of the total investments in fixed assets, and nearly $40 \%$ from the total business entities are recorded in the Skopje region (half of the medium - sized and over $70 \%$ of large enterprises). That is more than 3.5 times in comparison to the

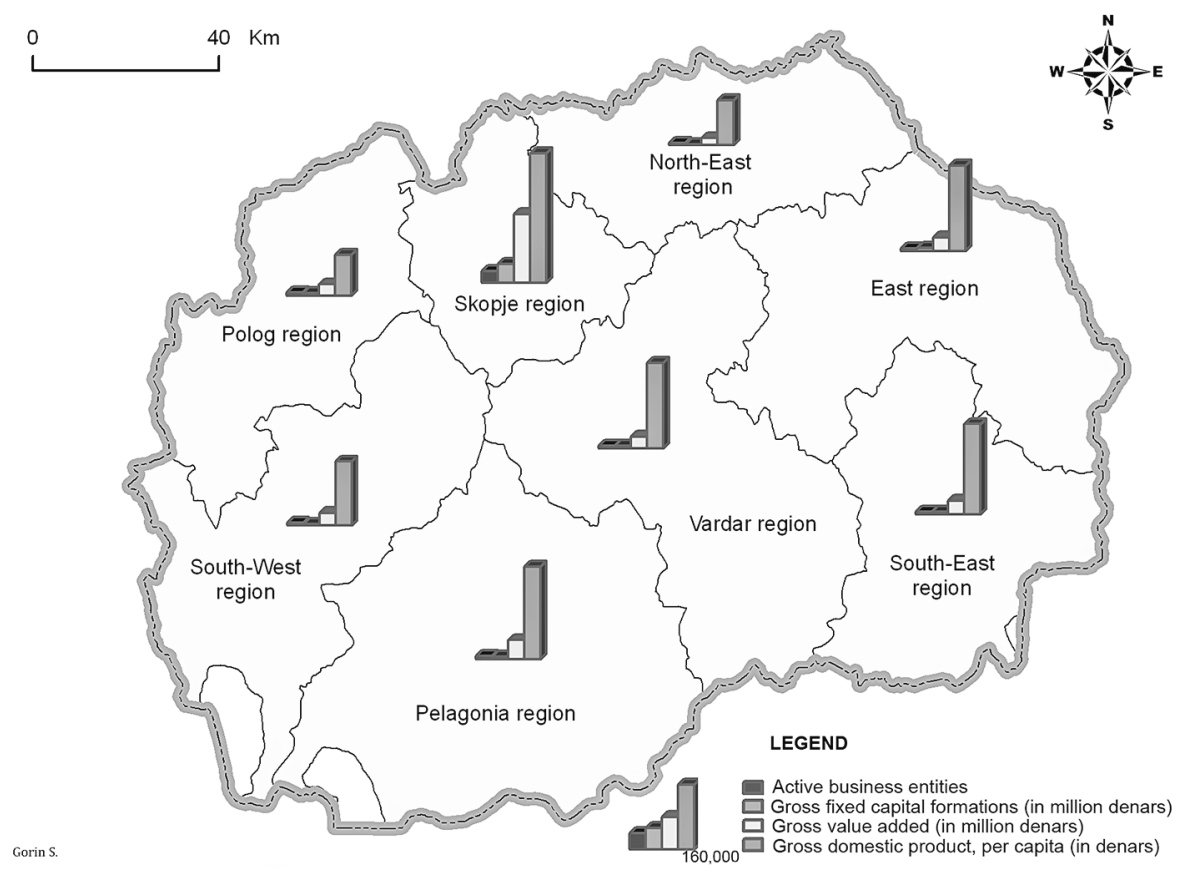

Map 2. Some economic indicators of the Republic of Macedonia by regions, 2010 Source: according to data from the State Statistical Office of the Republic of Macedonia 


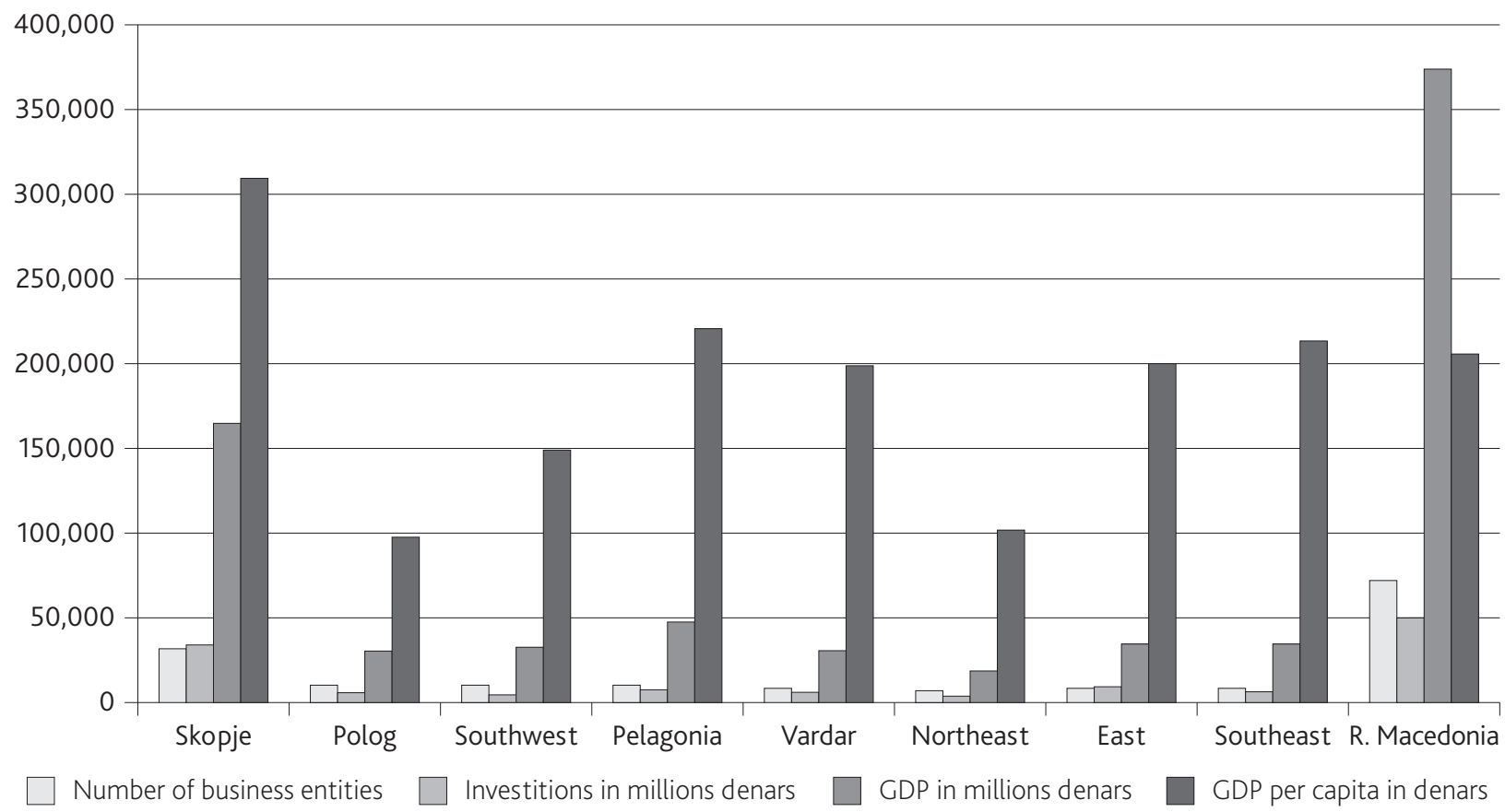

Figure 4. Some economic indicators of the Republic of Macedonia by regions, 2010 Source: according to data from the State Statistical Office of the Republic of Macedonia

Pelagonija region, as a second in the number of business subjects, or nearly 7 times more than the Northeast region. At the same time, over $1 / 3$ from the total investments in the industrial sector in the Republic of Macedonia are in this region that in relation to the Polog as a region with lowest number of investments rises for staggering 23.5 times, as in the analyzed year, and the years before.

Most of the investments are in the construction $(22.5 \%)$, industry $(20.9 \%)$ and trade $(14 \%)$. This enabled across all the analyzed years on average $30 \%$ of the total number of industrial workers in the country to be employed in the Skopje region (Madzevic, Apostolovska Toshevska, 2011). Although compared to other regions, Skopje has the smallest share of industrial workers compared to the total employment in the region, still the achieved industrial development, the large concentration of population with higher incomes have been a solid basis for the development of the service sector which absorbs $60 \%$ from the total employees in this region. Considering that in 2010 nearly $80 \%$ from all the investments in the trade in the entire country were in the Skopje region, the domination of the employed in the service sector and also in the trade sector will have a continuous growth.

At the same time, in the Skopje region nearly half of the total added value is accomplished, and has the highest gross domestic product per capita and is well above the state average and three times larger in relation to the Polog or the Northeast region (Figure 4). These are sufficient preconditions for a region that is affected, and which itself manifests economic polar- ization and economic and population gravitation in the whole country.

\section{Consequences from the polarization and proposed measures for overcoming the problems}

The overemphasized concentration of the population and the other potentials on a relative small area has different, complex and long term effects. The polarizing demographic development, growth of the interregional differences, emphasized urban - rural separation, continuous and emphasized concentration of the population in smaller number of settlements brings forth many demographic and socio - economic consequences. That contributes to creation of population and work - nonproductive areas in the rural environments, unfavorable age structure, rapid ageing and demographic emptying, etc. At the same time, this presents a limiting factor for the overall economic and social development, leads to misbalance in the regional development, to economic spatial imbalance, followed by several problems (as unused agricultural land, inadequate functional land use, imbalance in the reallocation of labor, imbalance in investments, environmental issues etc.) and conflict situations. The polarization of the economic - geographic components of the area (mountains - valleys, upper - lower parts of the basins, etc.) is followed by several functional, landscape and ecological changes of the physical - geographical complex and differentiation of the availability, accessibility and quality of the nat- 
ural potentials, and the general condition with the environments. (Milinčić, 2004).

The both faces of the polarization, that are mainly from a geographical character and has been continuously going on since the sixties form the past century up to today, are clearly visible in the example of the Republic of Macedonia. The anthropogenic and socio - economic units with great concentration of population and material goods have been created, but at the same time many ecological problems arise such as developmental thresholds, degradation, spontaneous occupation of the area and others that can reduce the value, attractiveness, prosperity, the ability for development of the settlements, economy and other different activities. The emphasized population - geographic differences between the settlements and the regions grow into limiting factors for realization of the other potentials and the economic - geographic prosperity as a whole.

Of course, certain steps towards overcoming the regional differences have been made, like building appropriate strategies for equal regional development, demographic strategies, employment strategies, migrations, and several efforts for opening and equipping of appropriate technological developmental industrial regions in this country, subsidizing the agriculture, packages for self-employment and business incubators, support of the family businesses, and encouragement of the small businesses. These have the objective through the organs of the state and local authority to act simulative and preventive in the area in order to provide appropriate demographic and economic growth and balance. The processes that are going on these recent years emphasize the need for changes in the territorial - administrative organization of the area. This will strengthen the hierarchical status of the individual settlements and their competence in organizing and planning the space to meet the needs of the individual and the society (Apostolovska Toshevska, Madzevic, 2012).

In future, the efforts have been aimed towards improvement of the infrastructural equipment, better living conditions, stopping of the migration and allowing for biological revitalization of the corresponding demographically fallen regions. At the same time, this is the basis for an economically sustainable development.

\section{Conclusion}

Characteristic for the demographic development of the Republic of Macedonia in the past several decades is the change in the components of the numeric dynamics, the decrease of the natural growth and the emigration of the population abroad. These process- es have resulted with slower growth of the population and changes in its demographic and socio - economic structure, especially on a regional scale, which will further affect the future regional development in the country.

The population growth of the cities that was a result of the natural growth, but also affected by the migration of population leaving the rural areas, led to their separation as zones of demographic growth. At the same time, the permanent emptying of the rural areas led to forming depopulation zones. The process of distribution and redistribution of the population, as an immediate effect from the influence of the demographic and spatial factors from the seventies of the twentieth century takes character of expressed polarization, creation of zones with concentration of the population and zones of depopulation. These are the two categories of spatial - demographic zones whose presence immediately reflects the overall spatial - functional relations and the overall development of the Republic of Macedonia.

From these reasons, today, in the Republic of Macedonia, on just one quarter on the territory of the country lives nearly half of the total population of the country. This uneven distribution of the population creates significant problems in the rational usage of the resources and encouragement of several social problems. Simultaneously, the uneven economic development of the country is still a push factor for the existing population. Despite the efforts of the national policy to undertake and implement its strategy for balanced economic growth and development, it is evident that in all the past years observed according the aforementioned economic indicators, the Skopje region presents itself as the most attractive for the business subjects and investments.

\section{References}

Apostolovska Toshevska B., Madzevic M. 2012. Demographic components of the Pelagonija region as benchmarks in the formation of the labor contingent, Demography: international journal for demographic and other social studies no. 9, 289-300; Faculty of Geography, University of Belgrade; (in English)

Kartalov, H. 1996. Sociology of the village. Faculty of Philosophy, Skopje; (in Macedonian)

Madzevic, M., Apostolovska Toshevska, B. 2011. Usage of the Mountain Areas in the Republic of Macedonia, Sustainable Development in Mountain Regions South eastern Europe, Springer 75-84; (in English)

Madzevic, M., Apostolovska Toshevska, B. 2011. Interdependency of the Urbanization and Industrialization in the Republic of Macedonia, Proceedings 
from the Scientific Symposium with International Participation Geography and Sustainable development, 22-25. 10. 2009, Ohrid; (in Macedonian)

Milinčić, M. 2004. The Economic - geographical and environmental polarization as a factor of new functional relations between areas. Bulletin of the Serbian Geographical Society, tome LXXXIV-No.2. 157164 Belgrade; (in Serbian)

Mladenov Ch. 2002. Population distribution in Bulgaria, Discussion papers, regional Challenges of the Transition in Bulgaria and Hungary, Centre for Regional Studies, Pećs, 20-26; (in English)

Nejasmić, I. 2011. Applied research in the Geography of population, Croatian Geographical Bulletin 73/1 29-37; (in Croatian)

Nurković S. 2006. Contemporary socio-geographical problems of the regional development of Bosnia and Herzegovina, ANNALES 16, 202-212; (in Serbian)

Vojković G. 2007. Population as an element of regionalization of Serbia, Belgrade; (in Serbian)
National strategy for regional development of Republic of Bulgaria 2012-2022, Sofia, 2012, p. 11

Project "Development of socio-economic analysis of the needs of the Regional Development Operational Program for the period 2014-2020" Bulgaria, p. 17 Regional profiles "Development Indicators", Sofia, 2012, p. 29

State Statistical Office, Census of population, households and dwellings in the Republic of Macedonia, 1994

State Statistical Office, Census of population, households and dwellings in the Republic of Macedonia, 2002

State Statistical Office, Statistical Yearbook of the Republic of Macedonia, 2011

SSO RM, Regions of the Republic of Macedonia, regional yearbook, 2012

www.stat.gov.mk

http://www.nationsencyclopedia.com/economies/Europe/Albania.html 